\title{
The Ascent of Sap and Transport of Food Materials in Trees.
}

$\mathrm{IN}$ opening the discussion on this subject in Section $K$ (Botany) of the British Association, on August 7, at Toronto, Prof. H. H. Dixon affirmed that the cohesion theory of the ascent of sap has recently received important support from the observation of continuous water-columns in the tracheæ of wilted plants by Holle and Bode, from the new determinations of the tensile strength of water by Renner and Ursprung, and from the observations of the collapse of the transmitting wood, and even of its constituent tracheæ under the tension developed during transpiration, and of their recovery on the rupture of the tensile water-columns. The water in the tracheæ, which passes into a state of tension, has been shown to contain carbohydrates and other foodstuffs. When the movement is upward in the trachex, due to transpiration and the supply from the roots, these foodstuffs are carried upwards in the stream. If for any reason a downward movement is originated these foodstuffs will evidently be carried downwards. Such a downward movement may be established by cutting a leaf of a transpiring plant under water. The downward movement may be visibly traced by adding eosin to the supply to the leaf. Thus in a short time the trachea of the tuber of a transpiring potato plant has been shown to become infected with eosin from one of its upper leaves. In this case transpiration from some leaf-areas has drawn the eosin solution from the cut leaf downwards into the tuber. In a similar manner, we may suppose that the foodstuffs manufactured by the leaves are transported. The reversal of the transpiration stream, artificially produced in the above experiment, probably often occurs naturally. This is suggested by the backward transport of hormones in the wood, recently demonstrated by Ricca in Mimosa, and probably occurring in other cases of transmitted stimuli.

The physical properties of the bast, and its available cross-section, render it impossible to suppose that the transference of foodstuffs takes place in the bast. An increase in the permeability of regions of the mesophyll around certain bundle-endings may render the contents of these cell-masses available as sources from which the tensile sap in the plant draws. It was assumed that the fluid thus introduced into the tracher is dragged backwards in the conducting tracts by the transpiration of other parts. Experiments were further quoted showing the change of permeability with temperature, and also the variations in the temperatures of leaves under natural conditions. It was contended that such temperature-changes may.be, in part at least, responsible for permeability - changes which originate backward movements in the water conduits, and hence facilitate the distribution of foodstuffs throughout the plant.

In conclusion, Prof. Dixon held that although it could not be affirmed that evidence amounting to a demonstration of the validity of the cohesion theory was available, nevertheless the theory as at present formulated seemed in harmony with the known facts.

In following with an account of recent experiments bearing on the transport of foods in woody plants, Dr. O. F. Curtis stated that when ringing experiments were performed during the growing season, materials necessary to growth would not move upwards through the xylem past the ring. Analyses and cryoscopic determinations indicated that the movement of sugars and other solutes was interfered with by the ring. When, just previous to spring-growth, rings were made at different distances from the tip of a branch, the growth above the rings was roughly proportional to the amount of food stored above the rings. Quantitative tests were held to indicate that the upward transfer of carbohydrates had been interfered with by the rings. It was further held that.when the xylem of a given region of the stem was isolated by rings through the phlœm from other tissues which would normally receive carbohydrates from the wood or supply the latter with carbohydrates, no movement of such carbohydrates out of or into this region of the xylem occurred. It was further stated that the normal upward movement of nitrogen and ashconstituents was interfered with, though not com pletely stopped, when the phlœm was cut. This occurred whether the ring was made in the early spring before new xylem and leaves were formed, or in midsummer after growth was practically complete. The evidence obtained from ringing experiments was held to indicate that the influence of the ring on the upward movement of nitrogen was independent of its effects on the organic content of this part above the ring or on transpiration.

In more or less direct opposition to the view expressed by Prof. Dixon, it was finally affirmed that experiments with spiral ringing of stems provide further supporting evidence for the opinion that foods and nutrients travel both upwards and downwards in higher plants chiefly in the phlœm.

Dr. D. F. MacDougal followed with a detailed statement of experiments conducted by the aid of a dendrograph. The purpose of his communication was to lay before the section his observations on variations in volume of trees, and in the movements of liquids within them. He stated that dendrographic measurements of several species of trees show that the trunks undergo variations in volume which may be correlated directly with the transpiratory activity of green surfaces, which in turn varies with the width of the stomatal slits. The period in which stomatal slits are widest is one of contraction of the trunk; closure of stomata is accompanied or followed by expansion of the trunks. Contraction of the trunks or stems of mesophytes and sclerophylls takes place in the daytime ; contraction of flattened or cylindrical stems of cacti takes place at night and expansion in the daytime, in reverse of the occurrences in the more general type.

The time or hour at which these two phases of variation prevail changes with the season. At the time of maximum growth, contraction in coniferous trees may begin within a half-hour after sunrise. Such reversible variations are modifiable by changes in relative humidity, by defoliation, girdling, topping, or any agency which alters transpiration or rate of conduction, and are explainable on the basis of Prof. Dixon's conception of the mechanism of the ascent of sap. The upward path of moving solutions of a basic dye, such as fuchsin, is found to be in the wood formed within the previous two years. When two layers are formed in a season conduction is chiefly in the one formed earlier. Whether the other layers are more available or suitable for the downward conduction of organic material is yet to be tested.

The amount of reversible variation in the diameter of a young pine may be $I$ part in 170 ; in the upper part of a tree approaching maturity I part in 900 ; in the basal region $\mathrm{I}$ part in $\mathrm{I} 700$; in a large root I part in 364 . As this variation takes place chiefly in the outer wood, it is found that in such recently formed layers the coefficient of expansion and contraction may be five to ten times greater than that of the trunk taken as a whole, as given above.

NO. 2866 , voL. I I 4$]$ 
In the discussion which followed Prof. Priestley stated that he had been a supporter of the cohesion theory of the ascent of sap, but that he was now so impressed with Copeland's criticism of the theory that he considered the latter incapable of meeting fully the criticism which it had raised. He desired to point out that Prof. Dixon had not replied to Copeland's challenge, demanding as it did an explanation as to how energy is employed in raising water in the stem. He further declared that no plantstructure had yet been shown to be capable of resisting the tensions which the cohesion theory supposed to be developed in the tree.

Prof. Overton expressed himself in general agreement with the cohesion theory, while Prof. V. H. Blackman considered that much work had yet to be done before a valid theory of the transport of organic substances could be constructed. There were difficulties in admitting that the wood furnished a downward path for organic substances, while at the same time it was engaged in transmitting the upward transpiration stream. In his opinion it seemed highly improbable that the bast is without a function. Whatever the function of the bast, he felt that it was associated with the downward transmission of foodstuffs.

In replying to the views which had been expressed, Prof. Dixon stated that in his opinion Dr. Curtis had not allowed sufficiently for the plugging arising in ringed stems. It was pointed out that the results of Dr. Curtis's experiments on branches with extirpated wood and on those the bast of which had been removed may, from the arrangements described, be explained on the known difference of resistance of wood to the transmission of water in a radial and in a longitudinal direction. In the opinion of Prof. Dixon the experi- ments described by Dr. Curtis did not necessarily indicate the transmission of food materials by the bast. Replying to Prof. Priestley it was pointed .out that the energy for raising water in plants is applied by the transpiring cells in contact with the upper terminations of the conducting tracts. This energy is supplied by the inflow of heat at the evaporating cells or by the stored energy in the cells themselves. The tensions developed in the water are withstood by the strength of the thickened tracheal walls and by the osmotic pressures developed in the adjoining cells.

In conclusion, Prof. Dixon expressed himself in agreement with Prof. Blackman regarding the need for fuller inquiry on the subject under discussion before any theory of the ascent of sap and the transport of organic materials in plants could be generally accepted. He held that it is quite in accordance with the known structure and properties of the tracheal tissues, that upward and downward currents may be simultaneously passing in adjacent tracts. The small resistance offered by the wood to the longitudinal movement of water, compared with that which it opposes to transverse movement, secures the jsolation of these two streams. Lest the unemployment of the bast should be used as a reproach against the cohesion theory of the transport of foodstuffs in the wood, he suggested that the companion-cells are glandular in function, and secrete enzymes which digest the colloids in the tracher. The sieve-tubes, he held, may be regarded as temporary reservoirs of these enzymes, while to the cells of the woodparenchyma and medullary rays may be allocated the functions of introducing these enzymes into the tracheæ and of abstracting food materials from them. J. McL. T.

\section{Aeronautical Research.}

THE issue of the report for the year I923-1924 of the Government Aeronautical Research Committee is of more than ordinary interest, since it records that the desire expressed by the Committee, that greater recognition should be given to the claims of pure research, has been recognised, in one important respect, by the reorganisation of the old directorate of research at the Air Ministry into two new departments, namely, a Directorate of Technical Development and a Directorate of Scientific Research.

It is gratifying that the Committee is able to record steady progress in the different subjects embraced by the science of aeronautics. Research having a direct application to aeronautics is financed by the Air Ministry; the remainder, having a more general application, is financed by the Department of Scientific and Industrial Research.

Investigations on elasticity and fatigue of various metals have been arranged in the Universities of Oxford, Birmingham, and Liverpool ; investigations on single-cylinder internal combustion engines have been started in the Universities of Cambridge, Durham, and Manchester, and in the City and Guilds (Engineering) College. In addition, there are the wholly subsidised researches carried out at the Royal Aircraft Establishment, the National Physical Laboratory, and the Air Ministry Laboratory in the Imperial College of Science and Technology, London.

The general field of work is so extensive that a local concentration on specific problems is necessary. In the year under review, one of the most important of the problems which has received attention is the control and stability of airplanes; the Committee justifies concentration on the attempt to secure lowspeed control by the continued occurrence of accidents in which "spinning" is a primary or secondary feature. In this direction, slow but steady progress is recorded. It had been suspected for some time that one of the main reasons for loss of control in a stalled airplane lay in the fact that ordinary ailerons, besides applying a moment to roll the machine, also cause it to turn, which turn eventually introduces moments which defeat the primary action of the ailerons and render them ineffective.

A larger rudder is thought to be a part solution : a rudder of ordinary size may be capable of providing all the turning moment required in normal flight, but may prove inadequate in stalled flight, in that it must become less effective through being shielded by the body when the incidence is large, and because larger moments are required from it in order to balance those set up by the wings and by the ailerons.

The difficult problems of the cause of detonation in engines, and of the steps necessary to eliminate this feature in high-compression units, has been under consideration, and attention has been given to the bearing of American work in this field of investigation. Experimental work on engines has been undertaken in the Government establishments and in the Ricardo Research Laboratory.

The Committee records the Air Council's agreement with the view that a higher standard of technical knowledge in all ranks of the R.A.F., and particularly among squadron officers, is necessary, and states that steps have been taken to organise instructional courses at Cambridge and the Imperial College with this end in view.

The report is of modest dimensions; its form is that of a 50 -page paper-covered pamphlet, and its issue price, 2s. $6 d$., through H.M. Stationery Office, seems somewhat high. 